\title{
Lymph node swelling combined with temporary effector $T$ cell re- tention aids $T$ cell response in a model of adaptive immunity
}

\author{
Sarah C Johnson ${ }^{1}$, Jennifer Frattolin ${ }^{1}$, Lowell T. Edgar ${ }^{1}$, Mohammad Jafarnejad ${ }^{2}$, James E. Moore \\ Jr. ${ }^{1}$ \\ 1 Department of Bioengineering, Imperial College London, London, United Kingdom \\ 2 Department of Biomedical Engineering, Johns Hopkins University School of Medicine, \\ Baltimore, MD, USA \\ * james.moore.jr@imperial.ac.uk
}

Keywords: Lymph node, effector $\mathrm{T}$ cells, agent based model, adaptive immunity, $\mathrm{T}$ cell dynamics

\begin{abstract}
Swelling of lymph nodes is commonly observed during the adaptive immune response, yet the impact on $T$ cell trafficking and subsequent immune response is not well known. To better understand the effect of macro-scale alterations, we developed an agent-based model of the lymph node paracortex, describing $\mathrm{T}$ cell trafficking and response to antigen-presenting dendritic cells alongside swelling-induced changes in $\mathrm{T}$ cell recruitment and egress, and regulation of expression of egressmodulating T cell receptor Sphingosine-1-phosphate receptor-1. Analysis of effector T cell response under varying swelling conditions showed that swelling consistently aided $\mathrm{T}$ cell activation. However, subsequent effector $\mathrm{CD} 8^{+} \mathrm{T}$ cell production could be reduced if swelling occurred too early in the $\mathrm{T}$ cell proliferative phase or if $\mathrm{T}$ cell cognate frequency was low due to increased opportunity for $\mathrm{T}$ cell exit. Temporarily extending retention of newly differentiated effector $\mathrm{T}$ cells, mediated by Sphingosine-1-phosphate receptor-1 expression, mitigated any negative effects of swelling by allowing facilitation of activation to outweigh increased access to exit areas. These results suggest targeting temporary effector $\mathrm{T}$ cell retention and egress associated with swelling may offer new ways to modulate effector TC responses in, for example, immuno-suppressed patients and optimisation of vaccine design.
\end{abstract}

\section{Introduction}

The lymphatic system is a network of organs and lymphatic vessels (LVs) that maintains fluid balance and delivers crucial antigen information to lymph nodes (LNs) for adaptive immunity initiation. LNs contain compartments populated by T cells (TCs), B cells, fibroreticular cells (FRCs), and lymphatic endothelial cells (LECs) [1. 2]. When antigens are presented (either suspended in lymph or captured by incoming antigen-presenting cells such as Dendritic Cells (DCs)), the LNs' physical environ- ment changes. Swelling of LNs is a well-known consequence of antigen presentation, but the effects of swelling on processes crucial for adaptive immunity are not well understood.

TCs and B cells mainly enter LNs by transmigrating from blood vessels in the paracortex, while lymph-borne DCs migrate into the paracortex across the sub-capsular-sinus (SCS) floor [3.4]. Typically, 1 in 10,000 naïve TCs express a complementary TC receptor to the antigen fragment presented by DCs within a MHCI 
(to $\mathrm{CD}^{+} \mathrm{TCs}$ ) or MHCII (CD4 $\left.{ }^{+} \mathrm{TCs}\right)$ molecule $[5,6]$. With sufficient affinity and stimuli, TCs undergo activation, secrete inflammatory and activation-facilitating cytokines and differentiate into effector and memory TCs [7|. The mechanisms driving LN swelling include DC presence, B cell signalling and trapping of nonactivated TCs [8-11]. Regardless of the trigger, within 2 days, TC exit rate drops ("LN shutdown"), blood flow to the LN increases, and inflammatory signalling results in a 3-5 fold increase in TC recruitment via high endothelial venules (HEVs) [12-15]. From 48-96 hours, LN mass increases 2-5-fold, accompanied by a similar increase in cellularity, and FRCs elongate to accommodate LN size increase [11. 16, 17]. Subsequent LEC and FRC proliferation allows maintenance of $\mathrm{LN}$ architecture during further expansion [10, 17, 18|. The LN blood vessels also grow, increasing blood vessel volume roughly proportional to overall $\mathrm{LN}$ volume, accompanied by further TC recruitment [9, 14, 19]. Between 2- and 5-days postimmunisation, antigen-presenting DC number in the LNs peaks, TC activation and proliferation is underway and TC egress increases 3-6 fold [10, 11, 20, 21]. Expansion of medullary and SCS areas aids increased TC egress [22]. Recruitment of TCs then declines, HEV, FRC and TC proliferation subsides, remaining effector TCs may undergo apoptosis and LNs return to baseline volume while memory cells recirculate [19].

Throughout these processes, TC egress is modulated by Sphingosine-1-Phosphate-1 receptor $\left(\mathrm{S}_{1} \mathrm{P}_{1} \mathrm{r}\right)$ expression and chemokine signalling axes. After entering the LN, TCs express $\mathrm{S}_{1} \mathrm{P}_{1} \mathrm{r}$ ) at low levels but begin $\mathrm{S}_{1} \mathrm{P}_{1} \mathrm{r}$ reexpression after 2 hours [23, 24|. TCs exit LNs by probing and subsequently entering cortical sinuses in the paracortex or the medullary interface, aided by chemotaxis [25, 26]. During inflammation, TC $\mathrm{S}_{1} \mathrm{P}_{1} \mathrm{r}$ expression is reciprocally regulated by CD69, an early TC activation marker. This mechanism contributes to the initial decrease in TC egress, termed LN shutdown, and later to the specific retention of ac- tivated TCs [15, 27]. Differentiated effector TCs re-express $\mathrm{S}_{1} \mathrm{P}_{1} \mathrm{r}$, facilitating egress [28].

The ability to investigate the importance of LN swelling in these processes is limited experimentally by a lack of means to modulate swelling without interfering directly with other aspects of adaptive immunity. We chose to develop an Agent Based Model (ABM) that could describe macroscale geometric changes, microscale TC and DC interactions and capture emergent behaviour by modelling the probabilistic behaviour of thousands of cells. Beyond the desire for a better understanding, we aim to provide a means for designing experiments that explore potential therapeutic means of modulating LN swelling.

Fixed-volume ABMs have provided insight into interactions relevant to vaccine design, for example, the effects of antigenic peptide separation on TC activation, influential aspects of TC-DC interaction, and memory TC production [29-33]. An ABM to investigate chemotactic influence included a form of paracortical expansion, where grid compartment number remained equal to TC number and exit portal number altered to maintain a mean TC residence time. This model suggested relative chemokine level is important but may underestimate changes in crowding and egress with swelling [34-36]. Simulations integrating a fixed-volume lattice-based model and a continuous model of chemokine diffusion showed early antigen removal and TC exit regulation affected the balanced system dynamics, indicating that macroscale swelling is likely to significantly affect micro-scale TC activity [37].

In summary, the careful trafficking and coordination of immune cell movements in the LNs, suggests LN swelling may significantly impact the adaptive response. We developed a computational ABM to investigate this hypothesis. The results suggest an important role for regulating early effector $\mathrm{TC}$ retention to maintain the benefits of LN swelling on overall effector TC response. 


\section{Materials and methods}

A

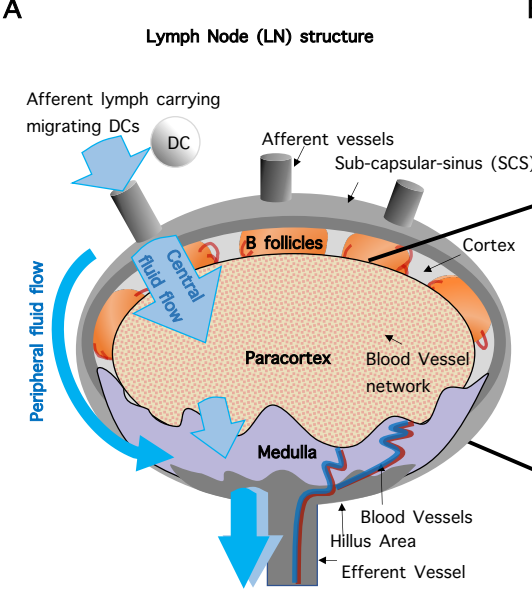

B
$C$

C

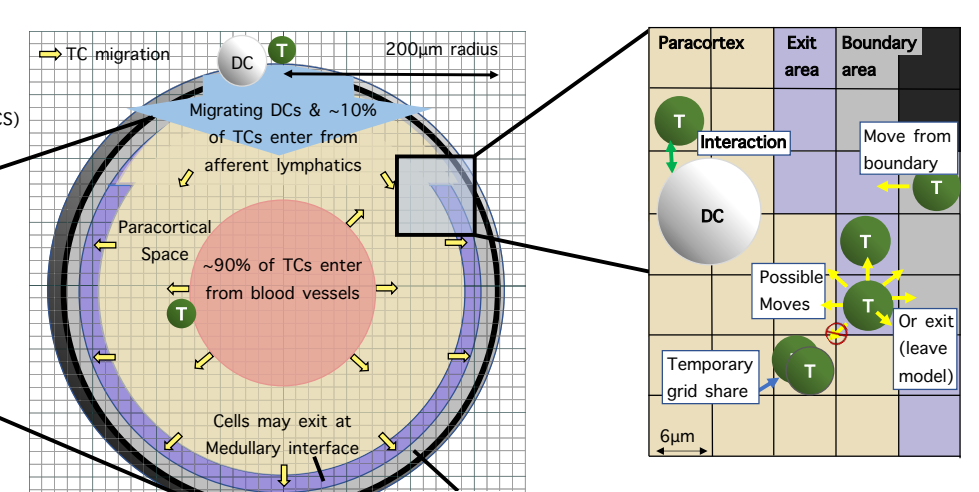

Figure 1: Model geometry and structure. (A) LN structure displaying arriving lymph containing agDCs. (B) TCs enter in the centre of the spherical paracortical model and exit near the interface with the medulla and SCS. The paracortex radius expands as a function of TCs present. (C) TCs move to adjacent grid-compartments, interact with neighbouring agents and are influenced by grid-compartment properties, which are updated each time-step.

\section{ABM geometry}

We aimed to replicate a murine LN by integrating experimentally obtained parameters. The paracortex was modelled as a sphere with initial radius $R_{0}=200 \mu \mathrm{m}$, derived from confocal images of murine LNs [2, 38]. Geometric symmetry was assumed so that one-half of total spherical geometry was modelled. The modelling domain was divided into cuboid grid compartments, with edge length $6 \mu \mathrm{m}$ (Fig 1 $\mathrm{C}$ ). For each grid compartment, we tracked which region of the paracortex was represented, such as 'exit', 'boundary' or 'outside'.

\section{Modelling Swelling}

Paracortical swelling or contraction was achieved by changing the region type that each grid compartment represented, while maintaining entry and exit areas as a percentage of the defined outer radius (Fig 2A). We collected data from murine experiments regarding change in LN mass and volume, TCs, structural cells, migrating DCs, TC recruitment and TC egress following antigenic stimulus application [9, 11, 12, 19, 20]. Based on these data we calculated paracortical volume as a sigmoidal function of TCs present (Fig A, S1 File). Initial TC increase is permitted without triggering significant swelling, reflecting initial inhibition of stromal cell proliferation by secretion of IFN type 1 [39]. A delayed volume increase in response to TC number is in agreement with the cell-signalling switch at day 2 to favour LN expansion, through mechanisms such as increased elasticity of the FRC network and LEC proliferation [11, 40].

\section{TC recruitment}

Under baseline conditions, TC recruitment rate was specified as $2000 \mathrm{TCs} /$ hour, with naive TC transit time $\left(\mathrm{T}_{\text {res }}\right)$ defined between 6-24 hours and a constant TC-to-compartment ratio assumed (1.2 in S1 File). In accordance with HEV 
images, $90 \%$ of TCs entered at 'entry' compartments designated as the inner half of the paracortical radius [41]. Remaining TCs entered via the SCS interface.

The volume of the entry grids was representative of blood vessel volume $\left(V_{B}\right)$, which changes proportionally with paracortical volume [9, 42]. We assumed TC recruitment rate $\left(\mathrm{T}_{i n}\right)$, is influenced by $\bar{V}_{B}$ (Eq. 1). Acute recruitment changes due to inflammation-induced signalling cascades at the HEVs were represented by inflammatory index, $\mathrm{I}_{F}$. This index affects TC influx when antigenic presence D (sum of MHCII, Eq. 2) rises above threshold, T1, the minimal DC number required to elicit a response [30]. The value of $\mathrm{I}_{F}$ increases proportionally with antigenic presence by a recruitment factor $\left(\mathrm{R}_{F}\right)$ up to a maximum inflammation-induced TC recruitment, threshold T2 (Eq. 3). TC influx was therefore defined as:

$$
T_{i n}(t)=\frac{N_{T}}{T_{r e s}} \quad I_{F}(t) \bar{V}_{B}(t)
$$

Where $\mathrm{N}_{T}$ is initial TC number, $\mathrm{T}_{\text {res }}$ is naïve TC transit time, $\mathrm{I}_{F}$ is the inflammatory index, and $\bar{V} \mathrm{~B}$ is normalised blood vessel volume. Threshold values for $\mathrm{T} 1, \mathrm{~T} 2$ and $\mathrm{R}_{F}$ were estimated from initial TC recruitment rate changes due to inflammation, whilst considering changes due to HEV growth and agDC number present [11, 15, 20, 43]. Inflammatory index $\mathrm{I}_{F}$ was calculated as:

$$
\begin{gathered}
D=\sum_{n=1}^{N_{D C}} M H C_{I I}(t) \\
I_{F}(t)= \begin{cases}1 & D \leq T 1 \\
1+R_{F} D & T 1<D \leq T 2 \\
1+R_{F} T 2 & D>T 2\end{cases}
\end{gathered}
$$

Where $\mathrm{N}_{D C}$ is number of agDCs present, $\mathrm{D}$ is the sum of MHCII carried by each agDC and
Recruitment Factor $\mathrm{R}_{F}$ is an estimated increase in recruitment rate.

\section{$\mathrm{TC}$ egress and $\mathrm{S} 1 \mathrm{P}_{1} \mathrm{r}$ expression}

We altered relative TC expression of $\mathrm{S}_{1} \mathrm{P}_{1} \mathrm{r}(\mathrm{SP})$, from a default value of 1 , under three conditions (Fig B in S1 File). Following TC entry into the paracortex $\mathrm{S}_{1} \mathrm{P}_{1} \mathrm{r}$ remained downregulated $\left(\mathrm{SP}_{i n}=0.1\right)$ for $45-180$ minutes, before re-expressing due to low paracortical S1P concentration [24]. A 'LN shutdown' mechanism was included by down-regulating $\mathrm{S} \mathrm{P}_{1} \mathrm{r}$ $\left(\mathrm{SP}_{\text {inflam }}=0.4\right)$ on all TCs when sufficient antigenic presence (summation of MHCII) was detected, estimated to correspond to 6 hours postagDC appearance. Activation-induced TC $\mathrm{S}_{1} \mathrm{P}_{1} \mathrm{r}$ down-regulation was represented by decreasing $\mathrm{S}_{1} \mathrm{P}_{1} \mathrm{r}$ expression 10 -fold when TCs initially activated $\left(\mathrm{SP}_{a c t}=0.01\right)$, increasing $\mathrm{S}_{1} \mathrm{P}_{1} \mathrm{r}$ expression as TCs differentiated into early effector TCs $\left(\mathrm{SP}_{\text {early }}=0.4\right)$, and further increasing expression when effector TCs underwent $\geq 8$ divisions $\left(\mathrm{SP}_{\text {late }}=1\right)$ [23, 44, 45].

\section{TC and DC motility and interaction}

DCs were modelled as $6 \mu \mathrm{m}$ radius spheres and interacted with TCs within a two-grid radius, up to a maximum number of TCs at once $\left(\mathrm{B}_{\max }\right)$. TCs were modelled as spheres of volume $150 \mu \mathrm{m}^{3}$, that initially occupied $60 \%$ of the total paracortex volume [46]. The frequency of antigen-specific (cognate) TCs $\left(\mathrm{F}_{\text {cog }}\right)$ was derived from in-vivo reports [6]. Each agDC presented a decaying MHC signal, and during interactions cognate TCs gained 'stimulation' (S) at rate $\kappa s$, proportional to MHC presented, while losing stimulation at rate $\lambda S$. Similar to previous models, probability of TC activation and, after a minimum of 4 proliferation's, differentiation into effector or memory TCs, was determined as a sigmoidal function of accumulated stimulation [31, 35, 47]. See S1 File for full rules. 


\section{Computation}

We build a class-based ABM (Fig C in S1 File) in java using RepastSimphony (repast.sourceforge.net) with repeated rules each time-step (Fig 2). Further UML descrip- tions are in S2 File. We carried out batch simulations on the Imperial College High Performance Computing cluster and analysed data in Matlab. Model code is available on GitHub at johnsara04/paracortex_model_johnson19
A

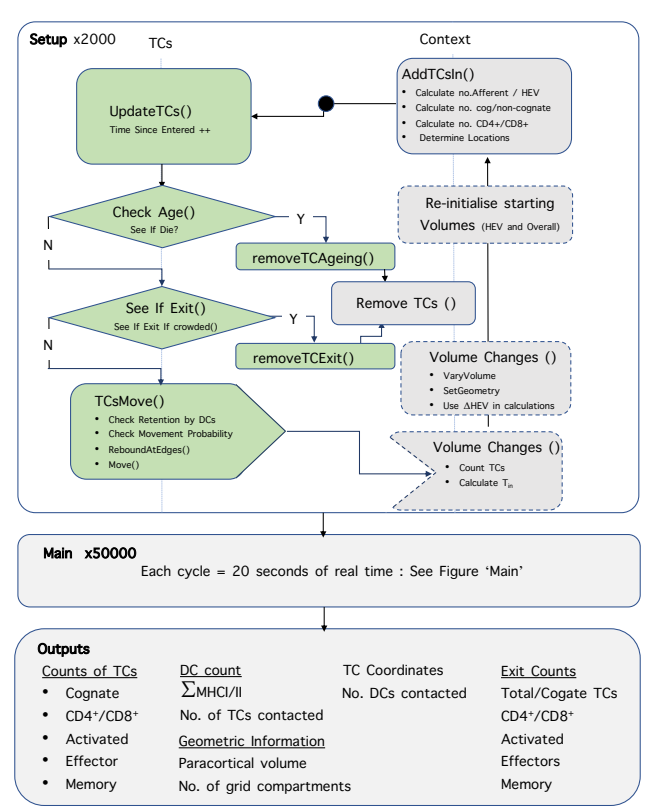

B

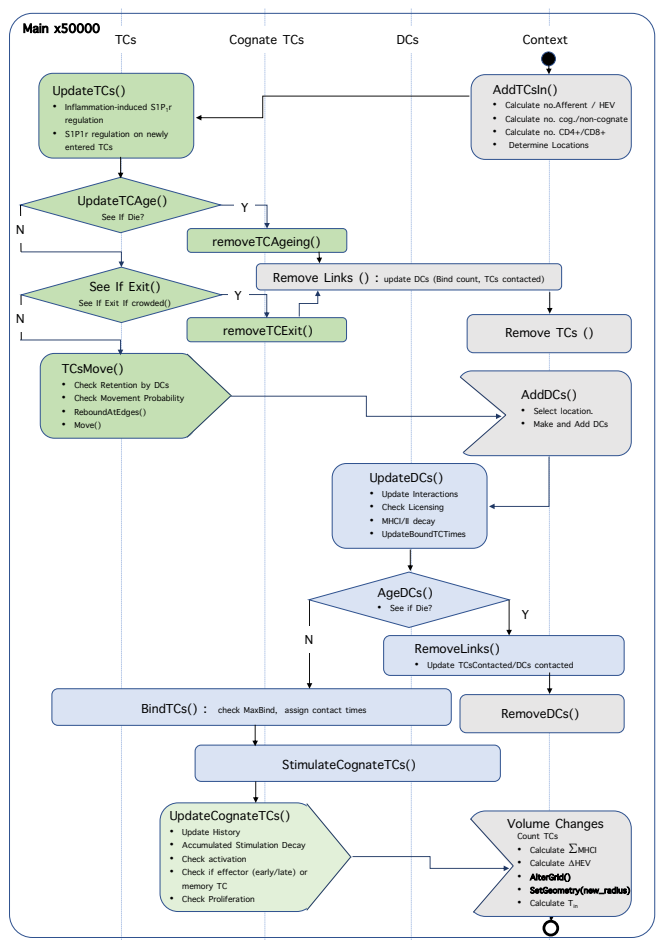

Figure 2: Structure of the model code. A) The model is initiated in the absence of stimulus, capacity for paracortical volume change is then introduced and variables storing starting volumes are updated. Agents represent cells (TCs and DCs), store interaction history and present state information. The 'Context' describes the environment and 'Projections' between agents allow information transfer. Each time-step represents 20 seconds. B) Following equilibration, the 'main' function calls a repeated series of sub-functions (see S2 File) describing DC arrival and TC response.

\section{Parameter selection and sensitivity analysis}

We estimated our parameters from published studies with inflammation-induced mice or previous relevant models (Table A in S1 File). To ensure awareness of influential but uncertain or biologically unconstrained parameters, we carried out a global sensitivity analysis. We used Latin Hypercube sampling to select 300 parame- ter combinations, simulated each set 3 times and recorded TC number (activated, effector, memory, effector exited and memory exited). Partial rank correlation coefficients (PRCCs) were calculated between each parameter and output for each day (3-13), assuming monotonic relationships [48]. We report significant PRCCs with strength greater than 0.2 (S4 File). 


\section{Validation and model robustness}

To ensure we did not overfit the model to one swelling scenario, we simulated four experiments that mimic in-vivo and/or in-vitro experiments, holding our parameter selection constant, aside from a single parameter. In each scenario, we compared the effects on TC activation and $\mathrm{CD}^{+}$and $\mathrm{CD} 8{ }^{+}$effector TC response to relevant published studies. We inhibited $\mathrm{S}^{1}{ }^{1} \mathrm{r}$ down-regulation on activated TCs as carried out by Gräler et al, and Lo et al [24.49]. We varied the initial proportion of cognate TCs, as carried out by Obar et al and Moon et al [50, 51]. We varied agDCs number as carried out by Kaech et al, and Martín-Fontecha et al, and we simulated early DC apoptosis, as carried out by Prlic et al 2006. [52-54].

\section{Results}

\section{The model produces realistic baseline TC motility and response to agDCs}

We confirmed that the calibrated model produced an average TC velocity $(n=200)$ of $13.1 \mu / \mathrm{min}$, reaching up to $24 \mu \mathrm{m} / \mathrm{min}$ (Fig 3A), in-line with murine in-vivo measurements [41. 55-58]. The mean TC paracortex transit time was 13.1 hours $(n=16,000)$, ranging from $20 \mathrm{~min}$ utes to $>60$ hours (Fig 3B), in-line with observations that $74 \%$ of $\mathrm{CD}^{+} \mathrm{TCs}$ and $64 \%$ of $\mathrm{CD}^{+}$ TCs transit murine LNs within a day [59]. The linear relationship between TC displacement versus square root of time, (Fig 3C) illustrated maintenance of random walk behaviour [60]. The motility coefficient (CM) was $63.2 \mu \mathrm{m}^{2} / \mathrm{min}$, which is within the $50-100 \mu \mathrm{m}^{2} / \mathrm{min}$ range observed in mice [61].
A

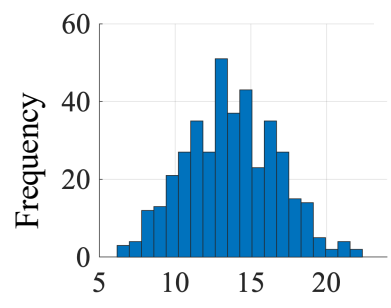

Mean TC velocity $\left(\mu \mathrm{m} \mathrm{min}^{-1}\right)$
B

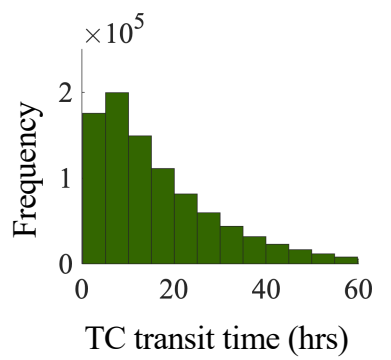

\section{C}

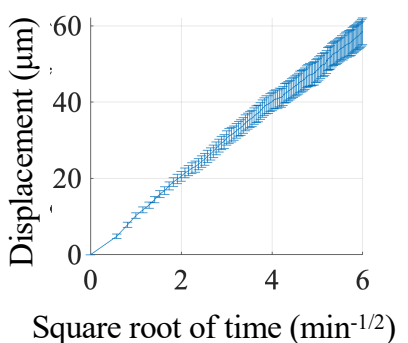

Figure 3: Baseline TC motility $(\mathbf{n}=\mathbf{2 0 0})$. A) Mean TC velocity. B) Most TCs transit in $<24$ hrs. C) Mean (+/-SEM) of TC displacement showed a linear relationship to the square root of time, indicating random walk behaviour.

TC responses to agDC stimuli corresponded well to data from in-vivo trials in mice, sheep and rats, displaying the expected phases of TC trafficking and response (Fig A in S3 File). TC numbers began to increase approximately 6 hours after initial agDC entry, and by day 11 had returned to within $15 \%$ of pre-stimulus values (Fig 4B), in-line with temporal responses observed in-vivo [11 12 20]. The appearance of activated, effector, and memory TCs began at 16-24 hours, day 3.5 and day 5 post-agDC entry, re- spectively, in agreement with in-vivo reports and cell-culture models [62,63]. Effector CD4 ${ }^{+}$TCs appeared 1-1.5 hours before $\mathrm{CD}^{+}$effector TCs (Fig $4 \mathrm{H}, \mathrm{I}$ ). As observed in-vivo, the peak cognate $\mathrm{CD}^{+}{ }^{+} \mathrm{TC}$ number was an order of magnitude higher than that of CD4 ${ }^{+}$TCs [64,65]. The contraction phase began at day 7 and continued through day 11 (Fig 4B). Increase in TC egress rate peaked a day later than the increase in TC entry rate (Fig $4 \mathrm{~F}, \mathrm{~J})$, corresponding well with invivo observations [16, 66. 
A

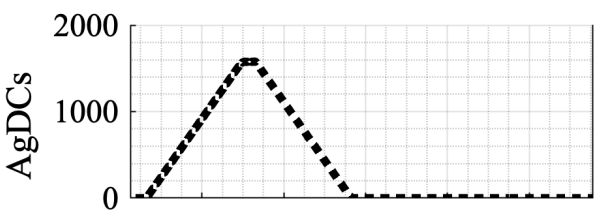

B

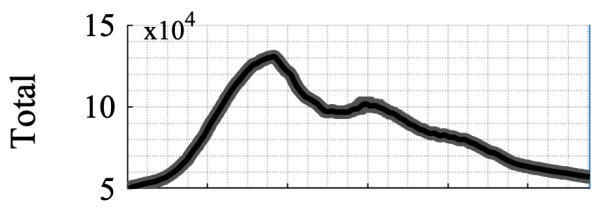

C

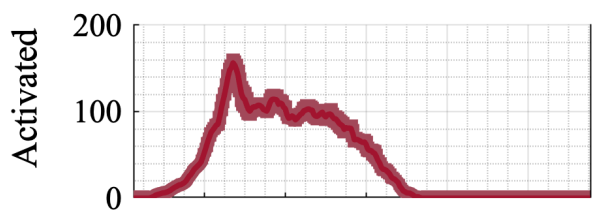

D

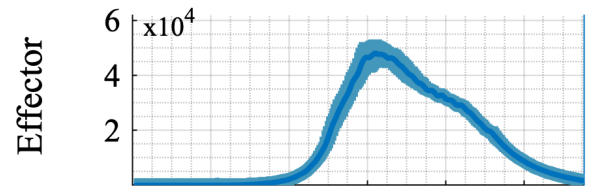

$\mathbf{E}$

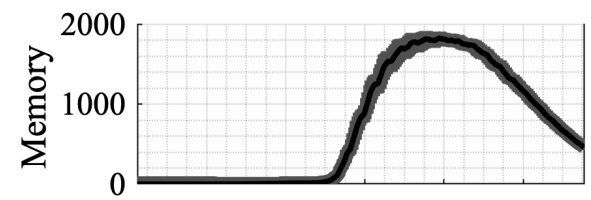

$\mathbf{F}$

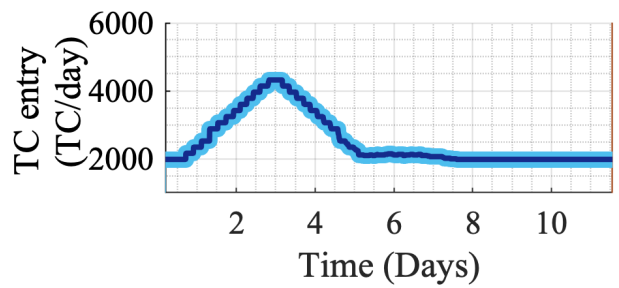

G

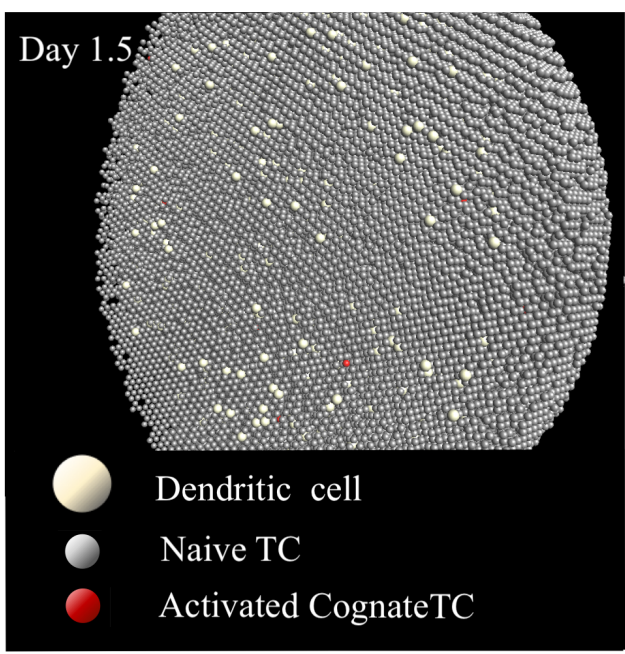

H

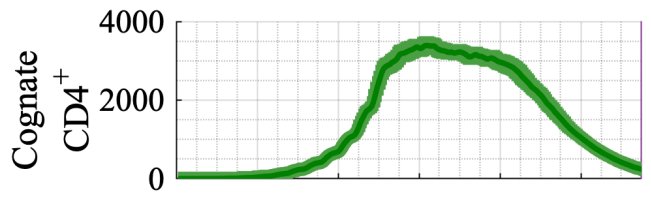

I

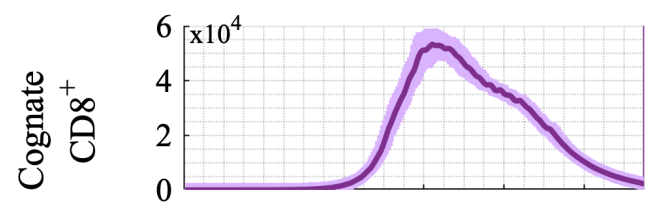

$\mathbf{J}$

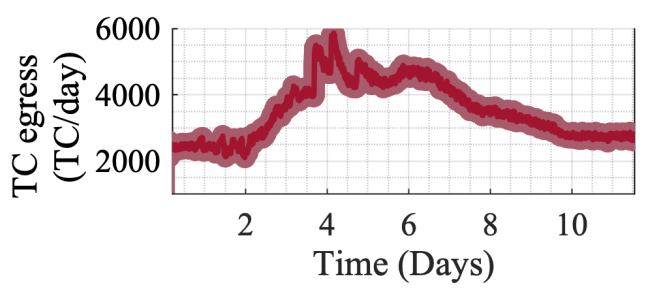

Figure 4: TC responses in the paracortex following entry of agDCs under baseline conditions. Average result with SEM of 12 simulations. A) Incoming agDCs. B) The total TCs number peaked at 3.5 days, comprising mainly of non-cognate naïve TCs. C) Activated TC appearance began 12 hours after the first agDCs entered. D) Effector TC number peaked at day 6. E. Memory TCs appeared at 5 days and $25 \%$ of the peak number remained at the simulation end. F) TC entry rate increased 2x, peaking at day 3. G. Model interface showing day 1.5 with agDCs present and TC activation initiated. H. Cognate $\mathrm{CD} 4^{+}$TCs began extensive proliferate at day 2.2. I. Cognate $\mathrm{CD} 8^{+}$ TCs began proliferation at day 4 and reached numbers $10 \mathrm{x}$ more than cognate CD4 ${ }^{+}$TCs. J. TC egress rate declined between day 1 and 2 , then increased $3 x$ by day 4 . 


\section{Model robustness}

Holding the default parameters and varying a single parameter at a time to mimic in-vivo and in-vitro experiments resulted in reasonable $\mathrm{TC}$ behaviour. For example, preventing $\mathrm{S}_{1} \mathrm{P}_{1} \mathrm{r}$ down-regulation post-antigenic stimulus detection in-silico reduced activated TC number by $60 \%-81 \%$ (Fig 5A). A study transferring activated $\mathrm{TCs}$ that over-express $\mathrm{S}_{1} \mathrm{P}_{1} \mathrm{r}$ into mice LNs, removing $\mathrm{S}_{1} \mathrm{P}_{1} \mathrm{r}$-mediated retention, resulted in $90 \%$ less activated TC retention compared to control mice when measured 15 hours later (Fig 5B [24]. A study using mice with constitutive TC expression of $\mathrm{S}_{1} \mathrm{P}_{1} \mathrm{r}$ showed a $40 \%$ reduction in activated TCs post-immunisation (Fig 5C) [49]. See S3 File for comparison of varying cognate frequency, agDC presence and duration of stimuli application.

The global parameter sensitivity analysis indicated that the dominant parameters in determining the target outcomes of TC activation, total TC effectors, and TCs exited were $\mathrm{F}_{\text {cog, }}$, $\mathrm{T}_{D \text { Cin }}, \mathrm{V}_{\max }$. The unconstrained parameters used to describe signal integration and parameterize activation or differentiation probability curves, were not identified as significantly influential in determining target outcomes ( $p>0.05$, $\left.\mathrm{R}^{2}<0.2\right)$ (Fig A and Tables A-C in S4 File).
A

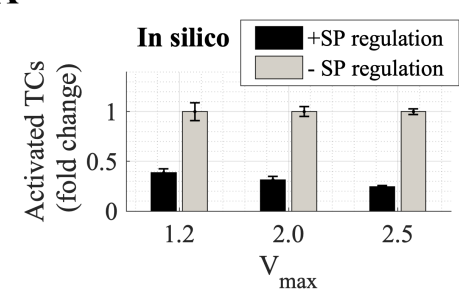

B

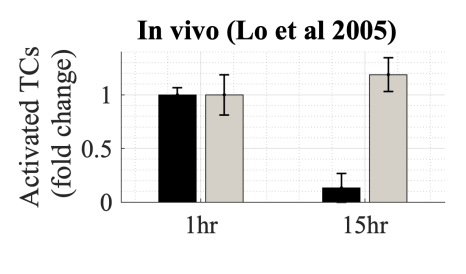

C

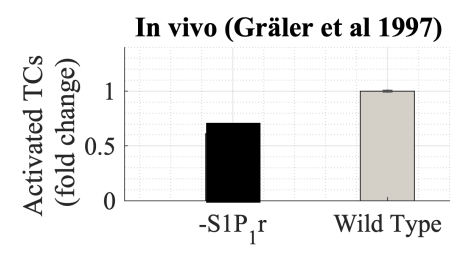

Figure 5: Comparing model predictions with reported in-vivo effects of $\mathrm{S}_{1} \mathrm{P}_{1} \mathrm{r}$ down-regulation on TC activation A. Simulation results $(\mathrm{n}=10)$ with and without $\mathrm{S}_{1} \mathrm{P}_{1} \mathrm{r}$ downregulation $(+/-\mathrm{SP}$ regulation) showed total activated TCs number reduced $60 \%, 72 \%$ and $81 \%$ (Mean+/-SEM) at $\mathrm{V}_{\max }=1.2,1.5$ \& 2. B. Pre-activated TCs over-expressing $\mathrm{S}_{1} \mathrm{P}_{1} \mathrm{r}$ (-SP regulation) were transferred into mice. Retention of activated TCs 15 hours later fell by $90 \%$ compared to transferred wildtype $\mathrm{TCs}$ (SP+ regulation). Adapted from Lo et al 2005. C) In mice with constitutive $\mathrm{S}_{1} \mathrm{P}_{1} \mathrm{r}$ expression, activated TC number in LNs $24 \mathrm{hrs}$ post-immunisation dropped by $40 \%$. Adapted from Gräler et al 1997.

\section{Paracortical swelling consistently aids TC activation}

When maximal swelling $\left(\mathrm{V}_{\max }\right)$ was varied from 1 to 2.8 , activated TC number doubled and positively correlated with $\mathrm{V}_{\max }\left(\mathrm{R}^{2}=0.96, \mathrm{p}<10^{-5}\right)$ (Fig 6A). The total number of effector TCs decreased by $15 \%$ (Fig 6B) and negatively correlated with $\mathrm{V}_{\max }\left(\mathrm{R}^{2}=0.86, \mathrm{p}<10^{-3}\right)$ but the number of effector TCs that exited by day 10 did not significantly vary (Fig E in S3 File).

Assessment of TC subgroups showed that the total cognate $\mathrm{CD} 8^{+} \mathrm{TCs}$ present decreased by $25 \%$ (Fig 6C), negatively correlating with $\mathrm{V}_{\max }\left(\mathrm{R}^{2}=0.855, \mathrm{p}<10-3\right)$ but there was no change in the number of exiting cognate $\mathrm{CD}^{+}$ TCs (Fig E in S3 File). Conversely, the number of cognate $\mathrm{CD}^{+}{ }^{+} \mathrm{TC}$ s that left the paracortex by day 10 increased by $30 \%$ and positively correlated with $\mathrm{V}_{\max }\left(\mathrm{R}^{2}=0.76, \mathrm{p}=0.001\right)$ (Fig 6D) but cognate $\mathrm{CD} 4^{+}$TC present did not varied significantly (Fig E in S3 File).

The peak TC recruitment rate positively correlated with $\mathrm{V}_{\max }$, meaning the absolute number of cognate TCs entering increased with swelling (Fig 6E). TC egress rate increased with $\mathrm{V}_{\text {max }}$ from day 3-6 (Fig 6F). Increased TC activation but decreased effector TC number remained when LN volume increased as a linear function of TCs (Fig A in S5 File). 
A

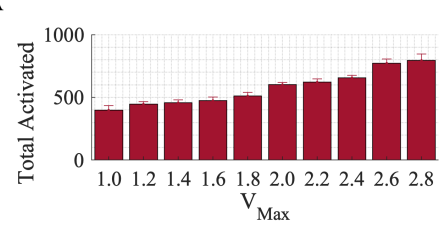

D

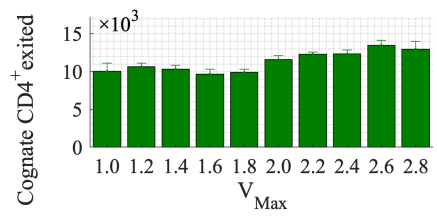

B

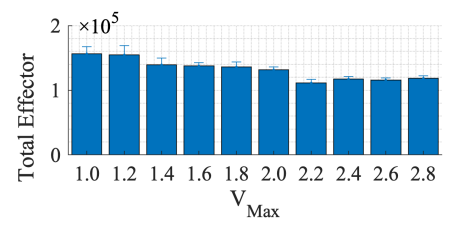

$\mathbf{E}$

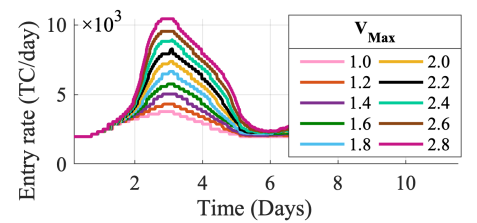

C

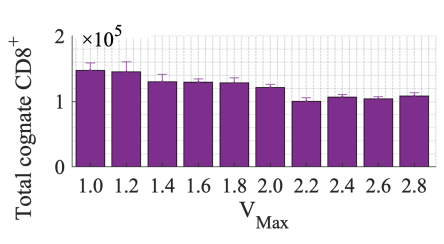

F

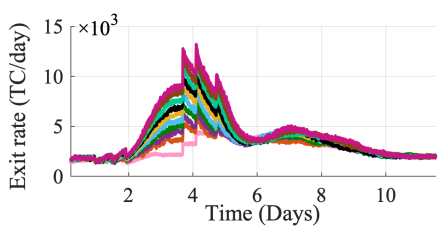

Figure 6: Changes in TC response in the paracortex when varying swelling. Between $\mathrm{V}_{\max }=1$ and $2.8, \mathrm{~A})$ total activated TCs doubled and positively correlated with $\left.\mathrm{V}_{\max }\left(\mathrm{R}^{2}=0.96, \mathrm{p}=1.07 \times 10^{-6}\right), \mathrm{B}\right)$ total effector TCs decreased $0.3 x$, negatively correlating with $\left.V_{\max }\left(R^{2}=0.86, p=1.23 \times 10^{-4}\right), C\right)$ total cognate $C D 8^{+}$TCs negatively correlated with $\left.\mathrm{V}_{\max }\left(\mathrm{R}^{2}=0.855, \mathrm{p}=1.28 \times 10^{-4}\right), \mathrm{D}\right)$ and total cognate $\mathrm{CD}^{+}$TCs that exited increased $1.3 \mathrm{x}$, positively correlating with $\left.\mathrm{V}_{\max }\left(\mathrm{R}^{2}=0.76, \mathrm{p}=0.001\right) . \mathrm{E}, \mathrm{F}\right)$ Peak entry and exit rate increased proportionally to $V_{\max }$. Results are the mean of $\mathrm{n} \geq 7$ simulations with SEM displayed.

Reduced effector TC response with swelling was not due to a lack of agDC availability

We then analysed the mean number of interactions with DCs by cognate and non-cognate TCs present each day from day 1 to 6 at different maximal swelling $\left(\mathrm{V}_{\max }=1.20,2.0\right.$ and 2.5). We found there was no decrease in the mean num- ber of agDCs that each cognate TC contacted on all days (Fig 7A). We also found a slight increase in the number of contacts by day 3 , a timepoint that corresponds with peak swelling. The mean number of short contacts by non-cognate TCs decreases with swelling (Fig 7B). These results suggest there is no decrease in availability of DCs to cognate cells with swelling.
A

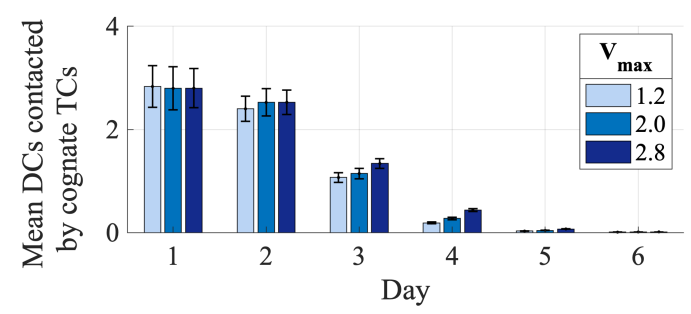

B

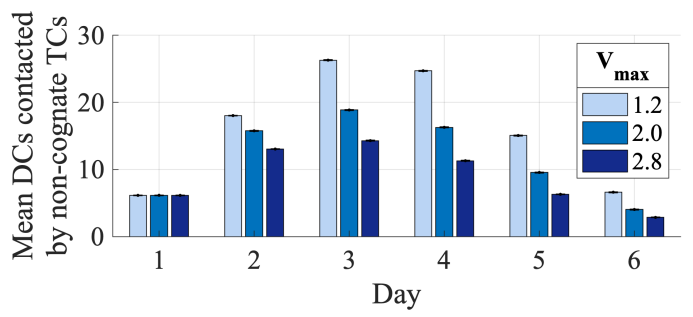

Figure 7: Changes in DC and TC contact with swelling from day 1 to 6 . With increased swelling the mean number of DCs contacted by (A) cognate TCs did not decrease but (B) non-cognate TCs contacted less DCs. 
Paracortical swelling can hinder effector TC production in some circumstances

We carried out simulations with a small or large maximal swelling $\left(\mathrm{V}_{\max }=1.2\right.$ or 2.5$)$ while applying a lower $\left(8 \times 10^{4} \mathrm{TCs}\right)$ or higher $\left(13 \times 10^{4}\right.$ TCs) $\mathrm{T}_{\text {mid }}$, making swelling occur relatively earlier or later (Fig 8A). Regardless of $\mathrm{T}_{m i d}$ value, at least $40 \%$ more activated TCs were recorded with a large $\mathrm{V}_{\max }$ compared to a small $\mathrm{V}_{\max }$ (Fig 8B). With an earlier (low $\mathrm{T}_{\text {mid }}$ ) and larger swelling, the total number of effector TCs and effector TCs exited dropped significantly $(\mathrm{p}<0.05)$
(Fig 8C). However, with later swelling, (high $\mathrm{T}_{m i d}$ ), a larger swelling no longer reduced effector TC number. This altered effector TC response was due to change in cognate $\mathrm{CD} 8^{+} \mathrm{TC}$ number, which showed the same pattern of results (Fig 8E). There was no change associated with $\mathrm{T}_{m i d}$ in cognate $\mathrm{CD} 4^{+} \mathrm{TC}$ response (Fig $8 \mathrm{~F}$ ). Varying maximal swelling and $\mathrm{T}_{m i d}$ over a wider range showed that the positive correlation of $\mathrm{T}_{\text {mid }}$ with effector TCs exited was only significant with a larger swelling $\left(\mathrm{V}_{\max }=2.5\right)($ Fig 8D), likely due to the greater impact of varying $\mathrm{T}_{\text {mid }}$ with larger swelling (Fig 8A).
A

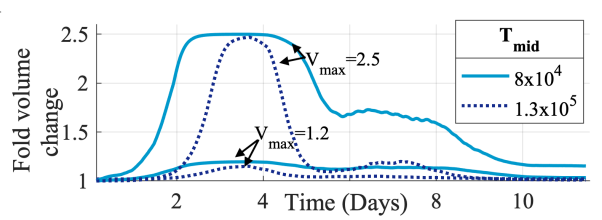

D

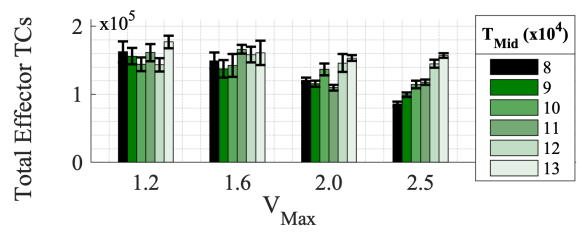

B

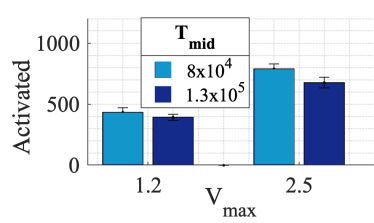

$\mathbf{E}$

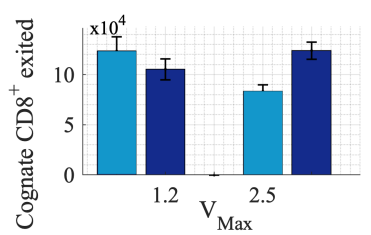

C

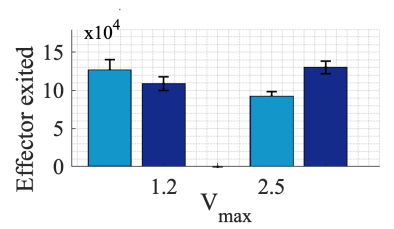

F

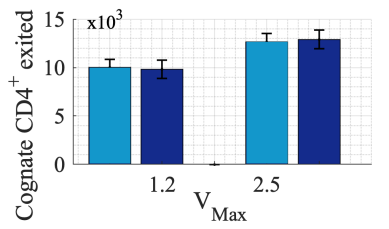

Figure 8: Varying the pattern of paracortical swelling (A) The paracortex swells earlier and for a longer duration with a low $\mathrm{T}_{\text {mid }}$. (B) Increased swelling aided TC activation. C) With a lower $\mathrm{T}_{\text {mid }}$, as swelling increased, number of effector TCs exited decreased. (D) Further simulations varying $\mathrm{T}_{\text {mid }}$ confirmed that at a large swelling $\left(\mathrm{V}_{\text {max }}=2.5\right)$, delayed swelling with a higher $\mathrm{T}_{\text {mid }}$ resulted in more total effectors TCs $\left(\mathrm{R}^{2}=0.97, \mathrm{p}=3 \times 10^{-4}\right)$. (E) This effect was due to altered CD8 ${ }^{+} \mathrm{TC}$ number as (F) CD4 ${ }^{+}$TC number increased with $\mathrm{V}_{\max }$ but was unaffected by varying $\mathrm{T}_{\text {mid }}$.

$\mathrm{S}_{1 \mathrm{P}}$ r-mediated temporary retention of early effector TCs increased TC response

When we increased $\mathrm{S}_{1} \mathrm{P}_{1} \mathrm{r}$ down-regulation by lowering $\mathrm{SP}_{\text {early }}$ from the estimated default value of 0.4 , a sustained increase in total TCs resulted, despite the action acting on early effector TCs only (Fig 9A). Unlike during simulations with default SP early (Fig 6), effector TC number did not decrease with swelling. Instead, when
$\mathrm{SP}_{\text {early }}$ was lowered from 0.4 to 0.1 , approximately $15 \%$ and $10 \%$ more effector TCs were produced with larger $\mathrm{V}_{\max }$ of 2.0 and 2.5 respectively. At every maximal swelling value $\mathrm{SP}_{\text {early }}$ inversely correlated with effector TC number $\left(\mathrm{R}^{2}=0.92,0.93,0.92, \mathrm{p}<0.005\right)$. Reducing $\mathrm{SP}_{\text {early }}$ from 0.4 to 0.05 doubled the number of effectors TCs exiting and increasing $\mathrm{SP}_{\text {early }}$ to 0.8 halved the number (Fig 9B).

When analysing the TC sub-populations, both $\mathrm{CD}^{+}$and $\mathrm{CD}^{+}$effector TCs that exited 
the paracortex by day 10 doubled when $\mathrm{SP}_{\text {early }}$ was decreased from 0.4 to 0.05 (Fig 9C, D). This indicated $\mathrm{CD}^{+}{ }^{+}$TCs do maintain further proliferative capacity in the model.

The number of TCs contacted by DCs increased as $\mathrm{SP}_{\text {early }}$ was decreased, but overall decreased with swelling, therefore was not a driving factor of increased effector TC number (Fig 9E). Implementation of an alternative model with non-specific constraint of TC egress by reducing expansion in the exit area also resulted in increased effector TC exit but produced unrealistic prolonged swelling above a 1.4-fold swelling (Fig B in S5 File).
A
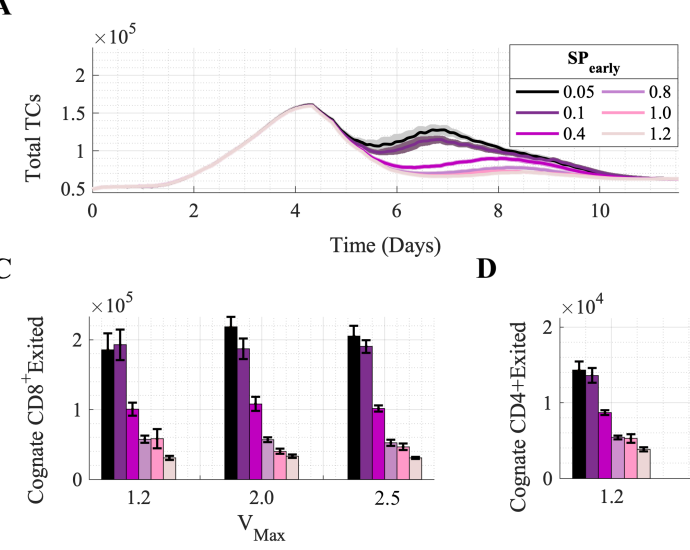

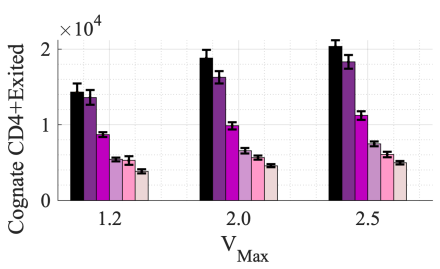

B

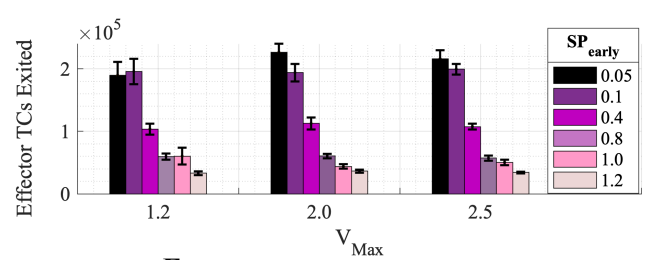

$\mathbf{E}$

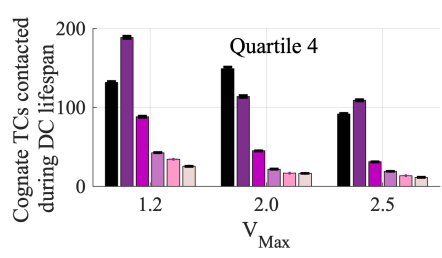

Figure 9: Temporary retention of effector TCs by modulating $S_{1 P} P_{1} r$ expression on newly differentiated TCs $\left(\mathbf{S P}_{\text {early }}\right)$. A) Reducing $\mathrm{SP}_{\text {early }}$ resulted in a higher total TC number. B) Number of effector TCs exited was affected more by $\mathrm{SP}_{\text {early }}$ than by $\mathrm{V}_{\max }$, negatively correlating with $\mathrm{SP}_{\text {early }}$ $\left(\mathrm{R}^{2}>=0.92, \mathrm{p}<0.005\right)$. SP early negatively correlated with $(\mathrm{C}) \mathrm{CD} 8^{+} \mathrm{TC}$ exited $\left(\mathrm{R}^{2}>0.92, \mathrm{p}<0.005\right)$ and (D) $\mathrm{CD}^{+}$TCs exited $\left(\mathrm{R}^{2}>0.91, \mathrm{p}<0.005\right)$.E). The mean number of cognate TCs contacted increased as $\mathrm{SP}_{\text {early }}$ was lowered to 0.1 at each $\mathrm{V}_{\max }$ but overall decreased with $\mathrm{V}_{\max }$.

Non-specific early LN shutdown with a doubling of LN volume did not significantly impact effector TC production

We also varied the degree of initial LN shutdown, by varying $\mathrm{SP}_{\text {inflam }}$ from 0.1 (90\% downregulation) to $\mathrm{SP}_{\text {inflam }}=1$ (no shutdown). We permitted a doubling of LN volume. Increasing non-specific $\mathrm{S}_{1} \mathrm{P}_{1} \mathrm{r}$ down-regulation from 60 to $90 \%$ resulted in a sharp, 3-fold higher peak in the total number of TCs (Fig 10A), which is less physiologically realistic than with our default parameters. As $\mathrm{SP}_{\text {inflam }}$ decreased, TC activation increased $\left(\mathrm{R}^{2}=0.83, \mathrm{p}=0.01\right)$ (Fig 10B), but no trend with total effector TCs was identified (Fig 10C). We found no correlation between increased LN shutdown and the mean number of contacts with DCs by cognate TCs present at day 3 but a positive correlation with DCs contacted by non-cognate TCs $\left(\mathrm{R}^{2}=0.93, \mathrm{p}=0.0017\right)$ (Fig 10D). 


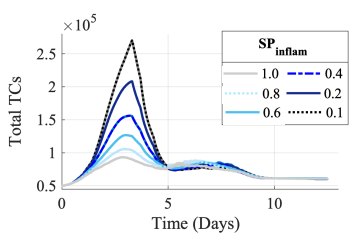

B

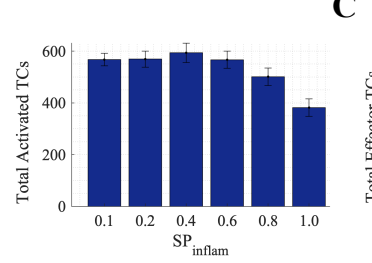

C

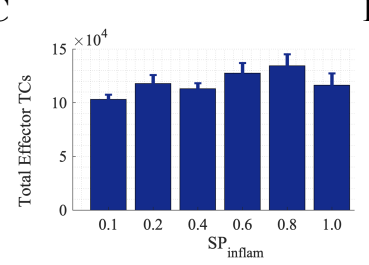

D

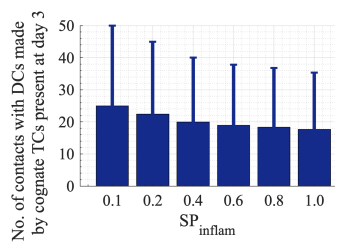

Figure 10: Varying LN shutdown by modulating initial inflammation-induced $\mathbf{S 1 P}_{1} \mathbf{r}$ downregulation $\left(\mathbf{S P}_{\text {inflam }}\right)$. Modulating $\mathrm{S}_{1} \mathrm{P}_{1} \mathrm{r}$ expression from 0 to $90 \%$ downregulation $\left(\mathrm{SP}_{\text {inflam }}=1\right.$ to $\left.\mathrm{SP}_{\text {inflam }}=0.1\right)$. A) total TC number decreases several fold but (B) TC activation increases $\left(\mathrm{R}^{2}=0.83\right.$, $\mathrm{p}=0.01)$ while $(C)$ effector TC production shows no trend. D) Non-cognate TCs contact more DCs as $\mathrm{SP}_{\text {inflam }}$ is increased $\left(\mathrm{R}^{2}=0.93, \mathrm{p}=1.7 \times 10^{-3}\right)$.

\section{Boosting TC response when cognate TC frequency is low}

Simulations using a 10-fold lower cognate TC frequency showed a larger decrease in effector TC number with swelling compared to the simulations with default cognition. With lower cognition, we observed a mean $73 \%$ fall with a 2-fold swelling, compared to a mean $17 \%$ decrease with 10-fold higher cognition (Fig 6B).
With $\mathrm{V}_{\max }=2.5$, we recorded a mean $33 \%$ fall compared to a $5 \%$ decrease with 10 -fold higher cognition (Fig E-vii in S3 File). We repeated the simulations with increased early effector TC $\mathrm{S}_{1} \mathrm{P}_{1} \mathrm{r}$ down-regulation $(\mathrm{SP}($ early $=0.1)$. This resulted in swelling of 2.0 or 2.5-fold benefiting the response. Assessment of TC and DC interactions showed that this was not due to increase in contact with DCs (Fig 11C).
A

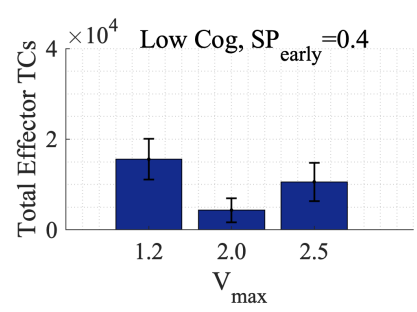

B

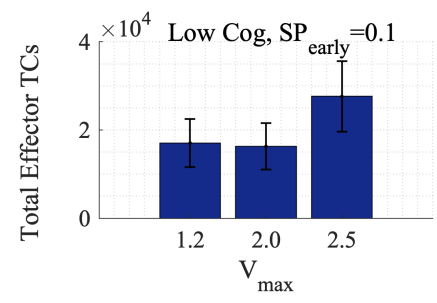

C

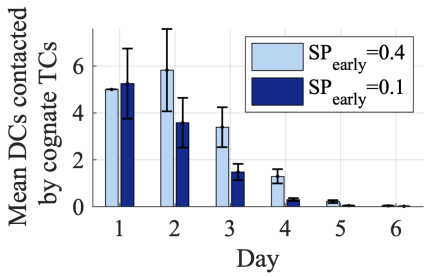

Figure 11: Swelling combined with increased retention of early effector TCs can improve response. With a 10-fold lower cognate frequency of $10^{5}$ and $(\mathrm{A})$ default estimated $\mathrm{S}_{\mathrm{P}} \mathrm{P}_{1} \mathrm{r}$ expression compared to (B) increased early effector $\mathrm{S}_{1} \mathrm{P}_{1} \mathrm{r}$ down-regulation. $\mathrm{C}$. The increased response is not due to increased DC access $\left(\mathrm{V}_{\max }=2.0\right)$.

\section{Discussion}

In this work, we aimed to better understand the effects of lymph node swelling in the formation of TC responses and identify key features that can influence TC behaviour. Our study builds on work using ABMs to investigate the impact of signal integration kinetics, TC migration and interaction dynamics on TC response with a focus on macroscale alterations and accompanying changes in egress and recruitment [29. 31, 33. 35|. 
We found that LN swelling consistently aids TC activation but increased swelling can inhibit subsequent effector TC response if it increased opportunity for effector TCs to egress prior to optimal proliferation. LN swelling aided increased TC recruitment and therefore a higher absolute number of cognate TCs in the paracortex, increasing TC activation probability in agreement with in-vivo TC recruitment studies [14]. In our model, swelling also presented a greater number of exit points and therefore increased opportunity for effector TC egress. Change in contact between TCs and cognate TCs was not a driving factor.

A key finding was that temporary $\mathrm{S}_{1} \mathrm{P}_{1} \mathrm{r}$ mediated retention of newly differentiated effector TCs could increase effector TC production in scenarios where effectors egress prior to reaching sufficient proliferation. The increased production was not due to increased contact with DCs (Fig 9E), and non-specific TC retention in the first few days had no impact on effector TC response (Fig 10). Swelling could also increase effector TC production when the exit area growth with swelling was constrained in alternative models (Fig B in S5 File).

We also found that, with low TC cognition rate, temporary $\mathrm{S}_{1} \mathrm{P}_{1} \mathrm{r}$-mediated retention of newly differentiated effector TCs could double effector TC response when combined with swelling, but swelling alone negatively impacted response. Here, swelling can increase initial TC recruitment and initial absolute number of cognate TCs but must be combined with increased temporary retention of newly differentiated cells to benefit response.

The temporary nature of this $\mathrm{S}_{1} \mathrm{P}_{1} \mathrm{r}$ modulation is crucial to increase effector TC number. Permanent inhibition of effector TC $\mathrm{S}_{1} \mathrm{P}_{1} \mathrm{r}$ expression has been carried out in-vivo, and therapeutically, $\mathrm{S}_{1} \mathrm{P}_{1} \mathrm{r}$ down-regulation is the mechanism of multiple sclerosis drug Fingolipid. This acts to indefinitely retain effector TCs in the LN to prevent autoimmune response [67]. Temporary down-regulation on selectively newlydifferentiated TCs may prove technically difficult, suggesting alternative means of retention is desirable [28].
In contrast to our results, transferring $10^{6}$ cognate TCs into murine LNs, whilst facilitating swelling by inducing FRC elongation and inhibiting FRC contraction enhanced subsequent TC proliferative response [17]. The authors suggest this may be due to reduced inhibition of TC activation by FRCs, or increased DC migration. Despite omission of these features, our model is in agreement with the increased TC activation. With an inflated initial cognate TC number that exponentially proliferated, the proportional effects of TC egress may be less as TC proliferative response is also relative to starting cognate TC frequency (Fig B in S3 File) [6, 50, 51]. We may also overestimate the negative effects of egress area availability with swelling, but highlighting the sensitivity of egress changes and temporary retention as a means to counteract sub-optimal responses remains an important result.

Our model contains unconstrained parameters that relate to signal gain and loss ( $\kappa$ s and $\gamma$ ), activation and differentiation probability curves $\left(\operatorname{Act} \mu 4^{+}, \operatorname{Act} \mu 8^{+}, \operatorname{Dif} \mu 4^{+}, \operatorname{Dif} \mu 8^{+}\right)$, TC recruitment and paracortical swelling (S4 File). The sensitivity analysis showed that the parameters populating activation and probability curves were not highly influential, and the influence of signal integration patterns has been the focus of previous modelling studies [31, 35, 47]. Our model was not over-fit to a single scenario as we also varied stimuli strength, duration and TC cognition rate with results correlating well with comparable in-vivo experiments.

Limitations of our model include lack of chemotactic influences, FRC network omission, and a simplified LN geometry. We omitted DC migration and LN-resident DCs, but our results indicate DC availability is not a limiting factor. We prioritised inclusion of $\mathrm{S}_{1} \mathrm{P}_{1} \mathrm{r}$ downregulation over the role of chemokine CCR7 because when CCR7 and $\mathrm{S1P}_{1} \mathrm{r}$ TC expression is inhibited in-vivo, TCs migrate to the paracortex boundary but lack of $\mathrm{S}_{1} \mathrm{P}_{1} \mathrm{r}$ expression prevents exit [28]. The critical influence of retention in our model suggests future iterations should include a wider range of retentive influences.

Several models suggest TC contacts are not significantly influenced by FRC network inclu- 
sion and we assumed that, regardless of the underlying FRC structure, TCs migrate with a random walk [55, 58, 61, 68, 70]. When the FRC is modelled as a small-world network, damaging the network by removing $50 \%$ of nodes can significantly affect effector TC response [71]. We assumed that FRC stretch and proliferation helps maintain FRC architecture during our modest swelling [11].

Model fidelity is also limited by a lack of information on exit-point availability during swelling, but the sensitivity to alterations in egress suggests that exit area change with swelling presents as a crucial area to focus future studies. Future model iterations including features, such as lymph flow and pressure alterations (along with fluid exchange with nodal blood vessels), could also significantly improve the representation of swelling, and thus TC egress and retention. It has been well-established that changes in hydrostatic and oncotic pressure differences across nodal blood vessel walls can reverse the net fluid exchange [72,73]. Afferent lymphatic flow, and thus DC number, to LNs also increases with immune response, as well as influencing chemokine concentration fields and likely mechanoresponsive cell expression of signalling molecules and receptors. A key next step is therefore to couple the ABM to a computational flow model.

\section{Conclusion}

Our results suggest that, although LN swelling aids TC activation, events that increase opportunity for TC egress prior to optimal proliferation, such as early LN swelling, can inhibit effector response. We found that temporary retention of newly-differentiated effector TCs may boost effector TC response. This effect is particularly of interest when initial TC response is small, for ex- ample, in immuno-suppressed patients, or desirable, such as when optimizing vaccine design to minimise antigen dose. Although permanent blockade of effector TC egress has been utilised to treat multiple sclerosis, temporary retention of effector TCs to boost subsequent effector TC production presents as a novel mechanism. Our model identified the importance of alterations in TC egress with swelling and emphasises the influence that retentive features, including factors such as chemokines, may have on effector TC response, which may be more practical in-vivo targets to manipulate.

\section{Supporting information}

S1 File. Supplementary Methods A. 1.1 LN swelling, 1.2 TC recruitment, 1.3 Agent migration, 1.4 Agent interaction and signal integration. Parameter Tables.

S2 File. Supplementary Methods B. UML diagrams.

S3 File.Supplementary Results A. Model calibration (Fig A), model validation (Fig B-D) and LN swelling results (Fig E).

S4 File.Supplementary Results B. Global sensitivity analysis. Fig A \& Tables A-C. Outputs are activated, effector and memory TCs present and effector and memory TCs exited.

S5 File. Supplementary Results C. Alternative models. 5.1 \& Fig A. A model with linear TC to LN volume relationship. $5.2 \&$ Fig B. Alternative models of TC crowding and egress.

\section{Competing Interests}

We declare we have no competing interests.

\section{Funding}

This study was supported by the Royal Society, The Royal Academy of Engineering, The Sir Leon Bagrit Trust and the U.S. National Institutes of Health (NIH) Grant U01-HL123420 .

\section{Acknowledgements}

The authors gratefully acknowledge the assistance provided by Dr Samira Jamalian and Willy Bonneuil. 
bioRxiv preprint doi: https://doi.org/10.1101/2020.06.19.161232; this version posted June 5, 2021. The copyright holder for this preprint

(which was not certified by peer review) is the author/funder, who has granted bioRxiv a license to display the preprint in perpetuity. It is made available under aCC-BY 4.0 International license.

\section{References}

1. Chang JE, Turley SJ. Stromal infrastructure of the lymph node and coordination of immunity. Trends in Immunology. 2014 12;36(1):30-39.

2. Mueller SN, Germain RN. Stromal cell contributions to the homeostasis and functionality of the immune system. Nature Reviews Immunology. 2009 07;9:618-29.

3. von Andrian UH, Mempel TR. Homing and cellular traffic in lymph nodes. Nature reviews Immunology. 2003 3;3(11):867-78

4. Braun A, Worbs T, Moschovakis G, Halle $\mathrm{S}$, Hoffmann $\mathrm{K}$, Bölter J, et al. Afferent lymph-derived $\mathrm{T}$ cells and DCs use different chemokine receptor CCR7dependent routes for entry into the lymph node and intranodal migration. Nat Immunol. 2011;12(9):879-87.

5. Blattman JN, Antia R, Sourdive DJ, Wang X, Kaech SM, Murali-Krishna K, et al. Estimating the Precursor Frequency of Naive Antigen-specific CD8 T Cells. The Journal of Experimental Medicine. 2002 03;195(5):657-664.

6. Jenkins MK, Moon JJ. The role of naïve $T$ cell precursor frequency and recruitment in dictating immune response magnitude. Journal of Immunology. 2012 05;188(9):4135-4140.

7. Pennock ND, White JT, Cross EW, Cheney EE, Tamburini BA, Kedl RM. T cell responses: naïve to memory and everything in between. Advances in Physio ogy Education. 2013 12;37(4):273-283.

8. Chyou S, Benahmed F, Chen J, Kumar V, Tian S, Lipp M, et al. Coordinated regulation of lymph node vascular-stroma growth first by CD11c+ cells and then by $\mathrm{T}$ and $\mathrm{B}$ cells. Journal of immunology. 2011 11;187(11):5558-67.

9. Kumar V, Scandella E, Danuser R, Onder L, Nitschké M, Fukui Y, et al. Global lymphoid tissue remodeling during a viral infection is orchestrated by a B cell-lymphotoxin-dependent pathway. Blood. 2010;115(23):4725-4733.

10. Yang CYY, Vogt TK, Favre S, Scarpellino L, Huang HYY, Tacchini-Cottier F, et al. Trapping of naive lymphocytes triggers rapid growth and remodeling of the fibroblast network in reactive murine lymph nodes. PNAS. 2014;111(1):E10918.

11. Acton SE, Farrugia AJ, Astarita JL Mourao-Sa D, Jenkins RP, Nye E, et al. Dendritic cells control fibroblastic reticular network tension and lymph node expansion. Nature. 2014 10;514(7523):498-502.

12. Tedla N, Wang H, HP M. Regulation of T lymphocyte trafficking into lymph nodes during an immune response by the chemokines macrophage inflammatory protein (MIP)-1 and MIP-1I2. The Journal of Imm. 1998;161(10):5663-72.

13. Hay JB, Hobbs BB. The flow of blood to lymph nodes and its relation to lymphocyte traffic and the immune response. Journal of Experimental Medicine. 1977;145(1):31-44.

14. Soderberg KA, Payne GW, Sato A, Medzhitov R, Segal SS, Iwasaki A. Innate control of adaptive immunity via remodeling of lymph node feed arteriole. Proceedings of the National Academy of Sciences of the United States of America. 2005 5;102(45):1631516320.

15. Cahill R, Frost H, Trnka Z. The effects of antigen on the migration of recirculating lymphocytes through single lymph nodes. J Exp Med. 1976;143(4):870-888.

16. Drayson MT, Smith ME. The sequence of changes in blood flow and lymphocyte influx to stimulated rat lymph nodes. Immunology. 1981;44:125-133.

17. Astarita JL, Cremasco V, Fu J, Darnell MC, Peck JR, Nieves-Bonilla JM, et al. The CLEC-2-podoplanin axis controls fibroblastic reticular cell contractility and lymph node microarchitecture. Nature Imm. 2015 01;16(1):75-84.

18. Gregory JL, Walter A, Alexandre YO, Hor JL, Liu R, Ma JZ, et al. Infection Programs Sustained Lymphoid Stromal Cell Responses and Shapes Lymph Node Remodeling upon Secondary Challenge. Cell Reports. 2017;18(2):406 - 418.

19. Kumar V, Chyou S, Stein J, Lu T. Optical projection tomography reveals dynamics of HEV growth after immunization with protein plus CFA and features shared with HEVs in acute. Frontiers in immunology. 2012;7(3):282.

20. Webster B, Ekland EH, Agle LM, Chyou S, Ruggieri R, Lu TT. Regulation of lymph node vascular growth by dendritic cells. J Exp Med. 2006;203(8):190313.

21. Tzeng TC, Chyou S, Tian S, Webster B, Carpenter AC, Guaiquil VH, et al. CD11chi Dendritic Cells Regulate the Re-establishment of Vascular Quiescence and Stabilization after Immune Stimulation of Lymph Nodes. The Journal of Immunology. 2010;184(8):42474257.

22. Tan KW, Yeo KP, Wong FHS, Lim HY, Khoo KL, Abastado JP, et al. Expansion of Cortical and Medullary Sinuses Restrains Lymph Node Hypertrophy during Prolonged Inflammation. The Journal of Immunology. 2012;188(8):40654080.

23. Matloubian $M$, Lo $C$, Cinamon G, Lesneski M, Xu Y. Lymphocyte egress from thymus and peripheral lymphoid organs is dependent on S1P receptor 1. Nature 2004:427(6972):355-60.
24. Lo C, Xu Y, Proia R, Cyster J. Cyclical modulation of sphingosine-1-phosphate receptor 1 surface expression during lymphocyte recirculation and relationship to lymphoid organ transit. Journal of Experimental Medicine. 2005;2(201):291-301.

25. Cyster J, Schwab S. Sphingosine-1phosphate and lymphocyte egress from lymphoid organs. Annual review of immunology. 2012;30:69-94.

26. Grigorova I, Schwab S, Phan T, Pham T Cortical sinus probing, S1P1-dependen entry and flow-based capture of egressing T cells. Nature Imm. 2009;10:58-65.

27. Hunter M, Teijeira A, Halin C. T cell trafficking through lymphatic vessels. Frontiers in Immunology. 2016;7:613.

28. Benechet AP, Menon M, Xu D, Samji T, Maher L, Murooka TT, et al. T cellintrinsic S1PR1 regulates endogenous effector T-cell egress dynamics from lymph nodes during infection. PNAS 2016 02;113(8):2182-2187.

29. Brown LV, Gaffney EA, Wagg J, Coles MC. An in silico model of cytotoxic T-lymphocyte activation in the lymph node following short peptide vaccination. Journal of the Royal Society, Interface. 2018 03;15(140):2018.0041.

30. Celli S, Day M, Müller AJ, Molina-Paris C, Lythe G, Bousso P. How many dendritic cells are required to initiate a Tcell response? Blood. 2012;120(19):39453948.

31. Gong C, Mattila JT, Miller M, Flynn JL, Linderman JJ, Kirschner D. Predicting lymph node output efficiency using systems biology. Journal of Theoretical Biology. 2013;335:169-184

32. Gong C, Linderman J, Kirschner D. Harnessing the Heterogeneity of T Cell Differentiation Fate to Fine-Tune Generation of Effector and Memory T Cells. Frontiers in Immunology. 2014;5:57.

33. Ziraldo C, Gong C, Kirschner DE, Linderman JJ. Strategic Priming with Multiple Antigens can Yield Memory Cell Phenotypes Optimized for Infection with Mycobacterium tuberculosis: A Computational Study. Frontiers in Microbiology. 2015;6.

34. Bogle G, Dunbar PR. Simulating T-cel motility in the lymph node paracortex with a packed lattice geometry. Imm Cell Biol. 2008 08;86(8):676-687.

35. Bogle G, Dunbar PR. Agent-based simulation of T-cell activation and proliferation within a lymph node. Imm Cell Biol. 2009 11;88(2):172-179.

36. Bogle G, Dunbar PR. On-lattice simulation of $T$ cell motility, chemotaxis, and trafficking in the lymph node paracortex. PloS one. 2012;7(9):e45258. 
bioRxiv preprint doi: https://doi.org/10.1101/2020.06.19.161232; this version posted June 5, 2021. The copyright holder for this preprint

(which was not certified by peer review) is the author/funder, who has granted bioRxiv a license to display the preprint in perpetuity. It is made available under aCC-BY 4.0 International license.

37. Baldazzi V, Paci P, Bernaschi M, Castiglione F. Modeling lymphocyte homing and encounters in lymph nodes. BMC Bioinformatics. 2009;10:387.

38. Kuka M, Iannacone M. The role of lymph node sinus macrophages in hos defense. Annals of the New York Academy of Sciences. 2014;1319(1):3846.

39. Lucas ED, Finlon JM, Burchill MA, McCarthy MK, Morrison TE, Colpitts TM, et al. Type 1 IFN and PD-L1 Coordinate Lymphatic Endothelial Cell Expansion and Contraction during an Inflammatory Immune Response. The Journa of Immunology. 2018;201(6):1735-1747.

40. Lucas ED, Tamburini BAJ. Lymph Node Lymphatic Endothelial Cell Expansion and Contraction and the Programming of the Immune Response. Frontiers in Immunology. 2019;10:36.

41. Girard JP, Moussion C, Förster R. HEVs, lymphatics and homeostatic immune cell trafficking in lymph nodes. Nat Rev Immunol. 2012;12(11):762-73.

42. Jafarnejad M, Woodruff MC, Zawieja DC, Carroll MC, Moore J. Modeling Lymph Flow and Fluid Exchange with Blood Vessels in Lymph Nodes. Lymphat Res Biol. 2015;13(4):234-247.

43. Mackay C, Marston W, Dudler L. Altered patterns of $\mathrm{T}$ cell migration through lymph nodes and skin following antigen challenge. European journal of Imm. 1992;22(9):2205-10.

44. Pham T, Okada T, Matloubian M, Lo C, Cyster J. S1P 1 receptor signaling overrides retention mediated by $\mathrm{Gi}$-coupled receptors to promote $\mathrm{T}$ cell egress. Immunity. 2008;28(1):122-133.

45. Garris CS, Blaho VA, Hla T, Han MH. Sphingosine-1-phosphate receptor $1 \mathrm{sig}$ nalling in T cells: trafficking and beyond. Immunology. 2014 07;142(3):347353.

46. Tasnim H, Fricke GM, Byrum JR, Sotiris JO, Cannon JL, Moses ME. Quantitative Measurement of Naïve T Cell Association With Dendritic Cells, FRCs, and Blood Vessels in Lymph Nodes. Frontiers in Immunology. 2018;9:1571.

47. Linderman JJ, Riggs T, Pande M, Miller M, Marino S, Kirschner DE. Characterizing the Dynamics of CD4+ T Cell Priming within a Lymph Node. The Journa of Immunology. 2010;184(6):2873-2885.

48. Marino S, Hogue IB, Ray CJ, Kirschner DE. A methodology for performing global uncertainty and sensitivity analysis in systems biology. Journal of Theoretical Biology. 2008;254(1):178 - 196.

49. Gräler $M H$, Huang $M C$, Watson $S$, Goetzl EJ. Immunological Effects of Transgenic Constitutive Expression of the Type 1 Sphingosine 1 Phosphate Receptor by Mouse Lym- phocytes. The Journal of Immunology. 2005;174(4):1997-2003.

50. Moon JJ, Chu HH, Pepper M, McSorley SI, Jameson SC, Kedl RM, et al. Naive CD4(+) T cell frequency varies for different epitopes and predicts repertoire diversity and response magnitude. Immunity. 2007 08;27(2):203-213.

51. Obar JJ, Khanna KM, Lefrançois L. Endogenous naive CD8+ $\mathrm{T}$ cell precursor frequency regulates primary and memory responses to infection. Immunity. 2008 06;28(6):859-869.

52. Kaech SM, Ahmed R. Memory CD8+ $T$ cell differentiation: initial antigen encounter triggers a developmental program in naïve cells. Nature Immunology. 2001 05;2:415-22.

53. Martín-Fontecha A, Sebastiani S, Höpken UE, Uguccioni M, Lipp M, Lanzavecchia A, et al. Regulation of Dendritic Cell Migration to the Draining Lymph Node. Journal of Experimental Medicine. 2003;198(4):615-621.

54. Prlic M, Hernandez-Hoyos G, Bevan MJ. Duration of the initial TCR stimulus controls the magnitude but not functionality of the CD8 $+\mathrm{T}$ cell response. Journal of Experimental Medicine. 2006;203(9):2135-2143.

55. Park E, Peixoto A, Imai Y, Goodarzi A, Cheng G. Distinct roles for LFA-1 affinity regulation during T-cell adhesion, diapedesis, and interstitial migration in lymph nodes. Blood. 2010;115(8):157281.

56. Boscacci R, Pfeiffer F, Gollmer K, Sevilla A. Comprehensive analysis of lymph node stroma-expressed Ig superfamily members reveals redundant and nonredundant roles for ICAM-1, ICAM-2, and VCAM-1 in lymphocyte homing. Blood. 2010;116(6):915-25.

57. Park C, Hwang I, Sinha R, Kamenyeva O. Lymph node B lymphocyte trafficking is constrained by anatomy and highly dependent upon chemoattractant desensitization. Blood. 2012;119(4):978-989.

58. Miller MJ, Wei SH, Parker I, Cahalan MD. Two-photon imaging of lymphocyte motility and antigen response in intact lymph node. Science. 2002;296(5574):1869-73.

59. Tomura M, Yoshida N, Tanaka J. Monitoring cellular movement in vivo with photoconvertible fluorescence protein 'Kaede' transgenic mice. PNAS. 2008;105(31):10871-6.

60. Sumen C, Mempel R, Mazo I, von Andrian U. Intravital Microscopy: Visualizing Immunity in Context. Immunity. 2004 09;21(3):315-329.

61. Beltman JB, Marée AFM, Lynch JN, Miller MJ, de Boer RJ. Lymph node topology dictates $\mathrm{T}$ cell migration behavior. Journal of Experimental Medicine. 2007;204(4):771-780.

62. Hugues S, Fetler L, Bonifaz L, Helft I Amblard F, Amigorena S. Distinct T cell dynamics in lymph nodes during the induction of tolerance and immunity. $\mathrm{Na}-$ ture Immunology. 2004 10;5:1235-42.

63. Kinjyo I, Qin I, Tan SY, Wellard CI, Mrass $\mathrm{P}$, Ritchie W, et al. Real-time tracking of cell cycle progression during CD8+ effector and memory T-cell differentiation. Nature Communications. 2015 02;6:6301.

64. Homann D, Teyton L, Oldstone MBA Differential regulation of antiviral T-cell immunity results in stable CD8+ but declining CD4+ T-cell memory. Nature Medicine. 2001;7(8):913-919.

65. Foulds KE, Zenewicz LA, Shedlock DJ Jiang J, Troy AE, Shen H. Cutting Edge: CD4 and CD8 T Cells Are Intrinsically Different in Their Proliferative Responses. The Journal of Immunology. 2002;168(4):1528-1532.

66. Hall J, Morris B. The immediate effect of antigens on the cell output of a lymph node. British journal of experimental pathology. 1965;46(4):450-454.

67. Chun J, Hartung HP. Mechanism of action of oral fingolimod (FTY720) in multiple sclerosis. Clinical neuropharmacology. 2010 03;33(2):91-101.

68. Miller MJ, Hejazi AS, Wei SH, Cahalan MD, Parker I. T cell repertoire scanning is promoted by dynamic dendritic cell behavior and random $\mathrm{T}$ cell motility in the lymph node. Proc Natl Acad Sci USA. 2004;101(4):998-1003.

69. Bousso P, Robey E. Dynamics of CD8+ $\mathrm{T}$ cell priming by dendritic cells in intact lymph nodes. Nature immunology. 2003;4:579-585.

70. Graw F, Regoes RR. Influence of the Fibroblastic Reticular Network on Cell-Cell Interactions in Lymphoid Organs. PLOS Computational Biology. 2012 03;8(3):1-9.

71. Novkovic M, Onder L, Cupovic J, Abe J Bomze D, Cremasco V, et al. Topological Small-World Organization of the Fibroblastic Reticular Cell Network Determines Lymph Node Functionality. PLOS Biology. 2016 07;14(7):1-20.

72. Adair TH, Guyton AC. Modification of lymph by lymph nodes. II. Effect of increased lymph node venous blood pressure. American Journal of Physiology-Heart and Circulatory Physiology. 1983;245(4):H616-H622.

73. Adair T, Guyton A. Modification of lymph by lymph nodes. III. Effect of increased lymph hydrostatic pressure. The American journal of physiology. 1985 11;249:H777-82. 